\title{
Analisis Kebutuhan ODD dan Family Caregiver dalam Komunitas ALZI
}

M. Anang Fardhyan A., Jeane P. M. Natumnea, Aryani Bachruddin, Yosua Jauhari, Aulia W. Putra

School of Business and Economics Universitas Prasetiya Mulya

JL. RA. Kartini (TB Simatupang), Cilandak Barat Jakarta Selatan, Jakarta 12430 Indonesia.

*. Corresponding Author: anang.fardhyan@gmail.com

\begin{tabular}{l|l}
\hline Abstract & ARTICLE INFO \\
\hline Based on data from World Alzheimer's Report 2015 there are 47 & Keywords: dementia, people \\
million people living with dementia (PWD) worldwide. PWD & with dementia, caregiver, \\
population in Indonesia is estimated at 2.3 million in 2030. Growth & needs, consumer behavior. \\
of the PWD population in Indonesia has an impact on the pattern of & \\
treatment for PWD that is applied. Treatment of PWD is strongly & \\
influenced by factors that influence consumer behavior in meeting & \\
their needs. This study describes a deep picture of PWD's needs and & \\
caregiver through focus group discussion (FGD) data collection & \\
techniques. This study aims to see whether the factors that & \\
influence consumerbehavior in meeting their needs can be the basis & \\
for a form of carefor PWD. & \\
\hline Abstrak & \\
\cline { 1 - 2 } Berdasarkan data dari World Alzheimer Report 2015 terdapat 47 & Keywords: demensia, orang \\
juta orang hidup dengan demensia di seluruh dunia. Populasi ODD & dengan demensia, caregiver, \\
di Indonesia diperkirakan sebesar 2,3 juta di tahun 2030. & kebutuhan, perilaku \\
Pertumbuhan populasi ODD di Indonesia berdampak pada pola & konsumen. \\
perawatan terhadap ODD yang diterapkan. Perawatan terhadap & \\
ODD sangat dipengaruhi faktor-faktor yang mempengaruhi & \\
perilaku konsumen dalam memenuhi kebutuhannya. Studi ini & \\
menjelaskan gambaran yang mendalam dari kebutuhan ODD & \\
maupun caregiver melalui teknik pengambilan data focus group & \\
discussion (FGD). Studi ini bertujuan untuk melihat apakah faktor- \\
faktor yang mempengaruhi perilaku konsumen dalam memenuhi \\
kebutuhannya dapat menjadi dasar untuk suatu bentuk layanan & \\
perawatan bagi ODD. & \\
\hline
\end{tabular}




\section{Pendahuluan}

Demensia merupakan kondisi kinerja otak manusia yang mengalami penurunan yang diakibatkan oleh beberapa jenis penyakit. Pada umumnya demensia belum dapat disembuhkan, namun bentuk perawatan dan aktivitas sehari-hari yang tepat dapat memperlambat laju demensia.

Pada tahun 2015, berdasarkan data dari World Alzheimer Report 2015 terdapat 47 juta orang dengan demensia (ODD) di seluruh dunia. Dari jumlah ini diproyeksikan akan meningkat menjadi lebih dari 131 juta pada tahun 2050. Dari total populasi penderita demensia di seluruh dunia, diestimasi terdapat 22,9 juta orang penderita demensia yang ada di Asia. Indonesia sebagai salah satu negara yang diklasifikasikan sebagai "low-middle income economy country", menjadi salah satu penyumbang populasi penderita demensia di Asia. Menurut data dari World Alzheimer Report tersebut, angka prevalensi penderita demensia di Indonesia akan semakin meningkat dari tahun 2015 kurang lebih sebesar 1 juta orang menjadi hampir 2,3 juta orang pada tahun 2030.

Caregiver sangat berperan penting dalam melakukan perawatan bagi lansia dengan demensia. Tanpa kemampuan dan pengetahuan yang memadai, usaha perawatan bagi ODD tidak akan memberi hasil dan kemajuan yang positif. Survei demensia yang dilakukan di Yogyakarta oleh Surveymeter pada tahun 2016 melibatkan tiga jenis responden, yaitu caregiver yang tinggal di lingkungan dengan ODD, caregiver yang tidak tinggal di lingkungan dengan ODD dan lansia non demensia. Dari penelitian tersebut, diketahui bahwa caregiver yang memahami tentang 10 gejala demensia jumlahnya kurang dari $16 \%$, hal ini menunjukkan bahwa tingkat kesadaran dan pengetahuan dari caregiver/keluarga pendamping tentang demensia khususnya terhadap lansia, masih sangat minim. Tingkat kesadaran maupun pengetahuan yang minim terhadap demensia akan berdampak pada efektivitas perawatan terhadap ODD. Bentuk pelayanan yang tidak efektif, akan mempengaruhi kondisi dan kualitas hidup ODD dan pada akhirnya juga berpengaruh pada kondisi psikologis dan kualitas hidup caregiver maupun keluarga pendamping.

Pemerintah Indonesia melalui Menteri Kesehatan RI, Prof. Dr. dr. Nila Farid Moeloek, SP.M(K) menetapkan salah satu strategi nasional adalah menurunkan angka prevalensi demensia dengan pendekatan siklus hidup melalui upaya kesehatan yang komprehensif, terpadu, dan efisien. Salah satu strategi yang diambil yaitu penerapan Program Kesehatan Lansia untuk meningkatkan mutu perawatan kesehatan dalam keluarga melalui homecare dan 
long-term care. Upaya penerapan Program Kesehatan Lansia ini yang salah satunya ditujukan untuk ODD harus disesuaikan dengan jalur perawatan demensia seperti gambar 1.

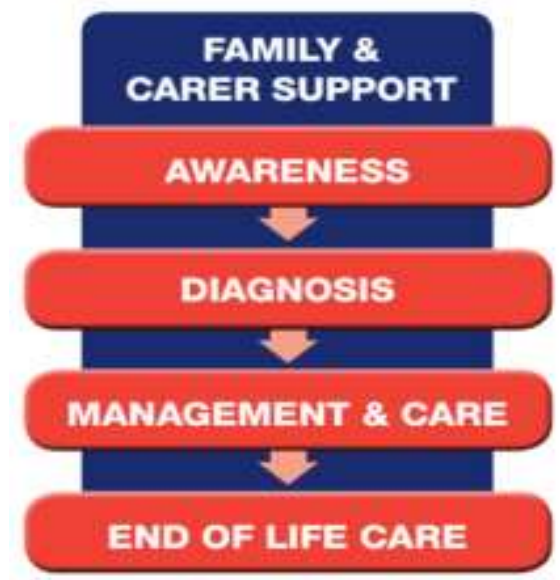

\section{Gambar 1. Dementia Pathaway}

Sumber: Dementia in the Asia Pacific Region 2014

Dementia pathaway ini dapat menjadi kerangka bagi strategi pemerintah untuk menjalankan program-program dalam meningkatkan awaraness masyarakat tentang demensia termasuk melakukan upaya langkah pencegahan dengan melakukan diagnosis secara dini dan mengambil langkah untuk mendapatkan perawatan yang efektif bagi ODD berusia lanjut.

Untuk mendukung program pemerintah tersebut, perlu dikaji lebih lanjut mengenai bentuk perawatan demensia yang efektif berbasis kebutuhan. Tujuan penelitian ini adalah memberikan gambaran secara mendalam mengenai kebutuhan dari ODD maupun caregiver berdasarkan pengalaman caregiver dan faktor-faktor yang mempengaruhi perilaku konsumen dalam memenuhi kebutuhannya. Manfaat dari penelitian adalah memberi informasi guna memperoleh bentuk layanan perawatan demensia yang efektif dan optimal berbasis pada kebutuhan ODD dan caregiver.

\section{Tinjauan Pustaka \& Pengembangan Hipotesa}

Demensia adalah sindrom - yang biasanya bersifat kronis atau progresif - di mana ada kerusakan fungsi kognitif (yaitu kemampuan untuk memproses pikiran) di luar apa yang mungkin diharapkan dari penuaan normal. Hal ini mempengaruhi daya ingat, pemikiran, orientasi, pemahaman, perhitungan, kapasitas belajar, bahasa, dan penilaian.. Gangguan dalam fungsi kognitif biasanya disertai, dan kadang-kadang didahului, oleh penurunan kontrol emosi, 
perilaku sosial, atau motivasi. Demensia menjadi salah satu penyebab utama kecacatan dan ketergantungan lansia terhadap caregiver dan keluarga mereka. Kurangnya kesadaran dan pemahaman tentang demensia, mengakibatkan stigmatisasi dan hambatan untuk diagnosis dan perawatan. Dampak demensia pada caregiver, keluarga, dan masyarakat dapat bersifat fisik, psikologis, sosial, dan ekonomi (World Health Organization 2017).

Caregiver terbagi ke dalam dua jenis yaitu formal dan informal caregiver. Formal caregiver adalah individu yang dibayar untuk melakukan tugas dalam memberikan perhatian, perawatan, maupun perlindungan bagi individu yang mengalami gangguan/sakit. Sementara itu yang dimaksud dengan informal caregiver atau yang sering disebut dengan family caregiver adalah individu yang memberikan bantuan bagi individu lain yang masih memiliki hubungan keluarga, maupun hubungan dekat seperti teman, kerabat atau tetangga (Bumagin 2009). Pada umumnya ODD memerlukan perawatan tingkat tinggi yang sebagian besar dilakukan oleh keluarga yang disebut informal caregiver. Tanpa adanya caregiver, ODD akan memiliki kualitas hidup yang buruk dan akan membutuhkan institutional care yang pada akhirnya akan berdampak pada kondisi finansial family caregiver (Brodaty 2009).

Banyak kendala yang dihadapi oleh family caregiver yang disebabkan oleh keharusan untuk memperhatikan keseimbangan antara kegiatan caregiving dengan tuntutan lainnya seperti membesarkan anak, karier, dan hubungan. Hal tersebut berdampak pada meningkatnya resiko untuk mengalami beban, stres, depresi, dan berbagai komplikasi kesehatan bagi family caregiver (Cassie \& Sanders 2008). Demensia sering dikaitkan dengan jam perawatan yang panjang dan pengasuhan yang ketat secara fisik. Banyak penelitian menemukan bahwa caregiver ODD memiliki tingkat beban yang lebih tinggi dibanding dengan caregiver lainnya (González-Salvador et.al., 1999). Selain itu penelitian lainnya menyebutkan bahwa kualitas hidup family caregiver dipengaruhi oleh burden family caregiver dalam merawat ODD. Semakin tinggi burden family caregiver maka semakin rendah kualitas hidup family caregiver, begitupula sebaliknya (Kumalasari et al., 2017).

Untuk memahami tentang burden family caregiver dapat dijelaskan dengan model Poulshock dan Deimling, dimana demensia mengarahkan beban perawatan yang dimanifestasikan sebagai tekanan melalui beberapa cara yang dapat memperparah/exacerbating (misalnya gangguan perilaku, fisik, sakit psikologis pada caregiver) atau menjadi lebih baik (misalnya dengan dukungan, mekanisme penanggulangan yang baik) 


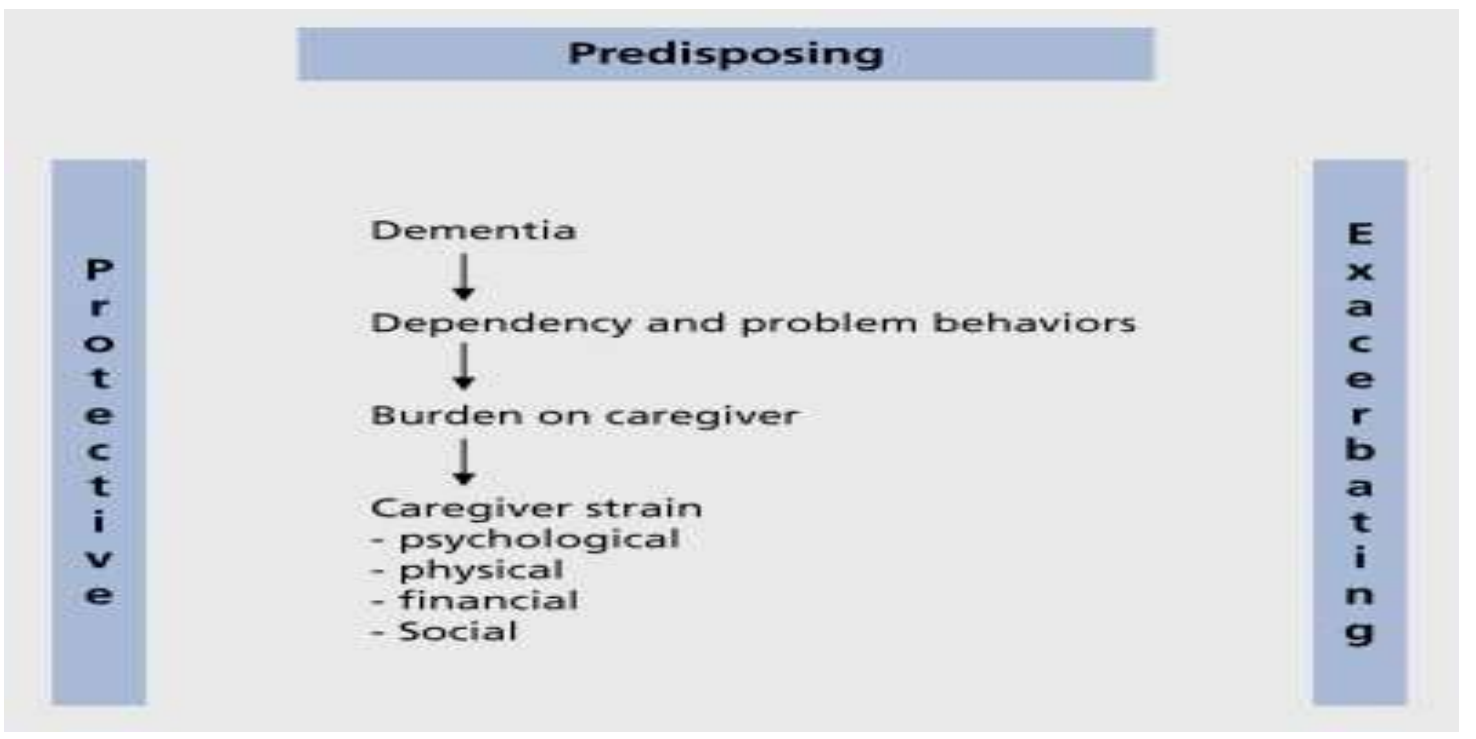

Gambar 2. Poulshock and Deimling model of caregiver strain

Sumber: Poulshock \& Deimling 1984

Berdasarkan permasalahan yang timbul baik bagi ODD maupun family caregiver maka peneliti memilih Theory Planned Behavior (TPB) yang dikembangkan oleh Ajzen (1986) untuk menganalisis perilaku individu dalam memperoleh kebutuhannya. Perilaku individu ditentukan oleh niat perilaku (intention) yang menunjukkan seberapa besar keinginan seseorang untuk melakukan sesuatu hal yang menimbulkan perilaku. Pada intinya Theory of Planned Behavior didasarkan pada asumsi bahwa manusia sebagai makhluk yang rasional menggunakan informasi-informasi secara sistematis. Setiap individu memikirkan keterkaitan dari tindakan mereka sebelum memutuskan untuk melakukan atau tidak melakukan perilaku-perilaku tertentu. Menurut Theory of Planned Behavior sebenarnya perilaku-perilaku berada pada suatu titik dalam suatu rangkain yang pada awalnya di bawah kendali kemudian menjadi tidak terkendali. Faktor-faktor pengendali dapat berasal dari faktor internal maupun eksternal. Faktor-faktor internal terdiri dari keterampilan, kemampuan, informasi, emosi, stres, dan lainnya. Sementara itu faktor-faktor eksternal meliputi situasi dan faktor-faktor lingkungan. 
Vol.01, No. 2, 2018

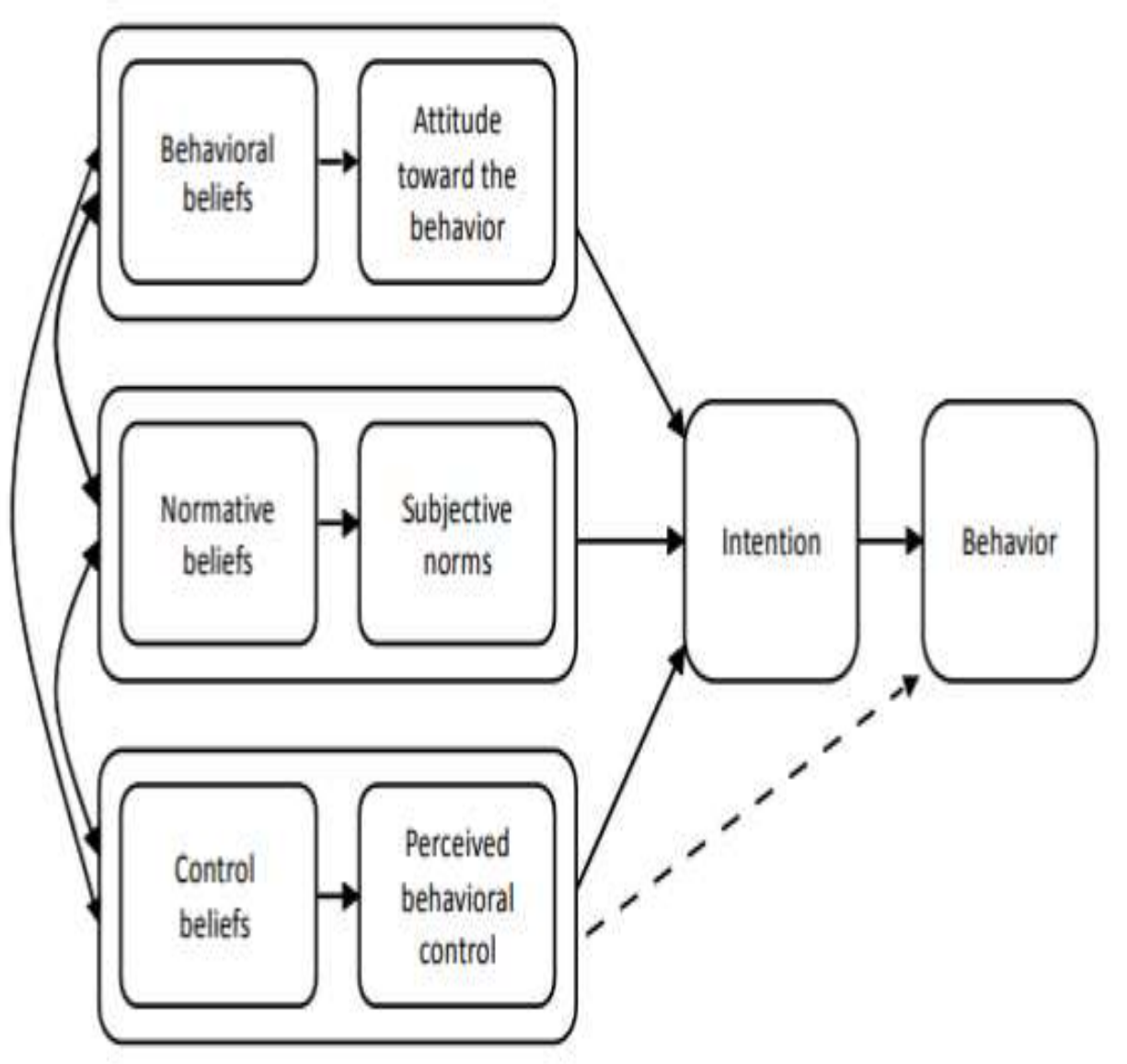

Gambar 3. Theory Planned Behaviour

Sumber: Ajzen 2005

Berdasar pada gambar 3, niat perilaku dalam TPB dipengaruhi oleh faktor sikap terhadap perilaku (attitude toward the behavior), faktor sosial (subjective norms), dan control perilaku yang dirasakan (perceived behavioral control). Gambar 3 menjelaskan bahwa model teoritik dari Theory Planned Behavior terdiri dari beberapa unsur yaitu :

(1) Latar belakang (background factors), yang terdiri dari usia, jenis kelamin, suku, status sosial ekonomi, suasana hati, sifat kepribadian, dan pengetahuan. Background facotrs dapat mempengaruhi sikap dan perilaku individu terhadap sesuatu hal. Menurut Ajzen background factors ini dikelompokkan ke dalam 3 faktor yaitu personal, sosial, dan informasi. Yang dimaksud dengan faktor personal adalah sikap umum seseorang terhadap sesuatu, sifat kepribadian (personality traits), nilai hidup (values), emosi, dan kecerdasan yang dimilikinya. Faktor sosial meliputi usia, jenis kelamin (gender), etnis, pendidikan, penghasilan, dan agama. Sedangkan faktor informasi terdiri dari pengalaman, pengetahuan, dan pemaparan pada media. 
(2) Keyakinan perilaku (behavioral beliefs) merupakan hal-hal yang diyakini oleh individu mengenai sebuah perilaku baik dari segi positif maupun negatif, sikap terhadap perilaku atau kecenderungan untuk bereaksi secara efektif terhadap suatu perilaku, yang ditunjukkan dalam bentuk suka atau tidak suka terhadap perilaku tersebut.

(3) Norma subjektif (subjective norm) adalah sejauh mana pandangan orang lain terhadap perilaku yang akan dilakukan (normative belief) mempengaruhi motivasi orang tersebut untuk melakukannya. Jika individu merasa untuk menentukan apa yang akan dia lakukan, bukan ditentukan oleh orang lain yang ada di sekitarnya, maka dia akan mengabaikan pandangan orang tentang perilaku yang akan dilakukannya karena itu merupakan hak pribadinya.

Fishbein \& Ajzen (1975) menggunakan istilah motivation to comply untuk menggambarkan kejadian ini, apakah individu mematuhi pandangan orang lain yang berpengaruh dalam hidupnya atau tidak.

(4) Keyakinan normatif (normative beliefs), keyakinan ini berkaitan langsung dengan pengaruh dari lingkungan. Ajzen menyatakan bahwa keputusan individu dapat dipengaruhi oleh faktor lingkungan sosial khususnya orang-orang yang berpengaruh bagi kehidupan individu (significant others).

(5) Persepsi kemampuan mengontrol (perceived behavioral control), adalah keyakinan (beliefs) bahwa individu pernah melaksanakan atau tidak pernah melaksanakan perilaku tertentu, individu memiliki fasilitas dan waktu untuk melakukan perilaku itu, dan selanjutnya individu membuat perkiraan atas kemampuan dirinya apakah dia mampu atau tidak untuk melaksanakan perilaku tersebut.

(6) Keyakinan bahwa suatu perilaku dapat dilaksanakan (control beliefs) dipengaruhi dari beberapa hal yakni pertama adalah pengalaman melakukan hal yang sama sebelumnya atau pengalaman yang diperoleh karena melihat orang lain (seperti teman atau keluarga dekat) melaksanakan perilaku tersebut. Selain pengetahuan, ketrampilan, dan pengalaman, keyakinan individu mengenai suatu perilaku akan dapat dilaksanakan juga ditentukan oleh ketersediaan waktu untuk melaksanakan perilaku tersebut, tersedianya fasilitas untuk melaksanakannya, dan kemampuan untuk mengatasi setiap kesulitan yang dapat menghambat dalam pelaksanaan perilaku.

Niat untuk melakukan perilaku atau intention merupakan kecenderungan seseorang untuk memilih melakukan atau tidak melakukan sesuatu pekerjaan. Niat ini dipengaruhi oleh sejauh mana individu memiliki sikap positif pada perilaku tertentu, dan sejauh mana kalau dia 
memilih untuk melakukan perilaku tertentu itu, maka akan mendapat dukungan dari orangorang lain yang berpengaruh dalam kehidupannya.

Maka penelitian ini melihat bahwa faktor-faktor dalam Theory Planned Behavior yang meliputi keyakinan perilaku (behavioral belief), keyakinan normatif (normative beliefs), dan keyakinan bahwa suatu perilaku dapat dilaksanakan (control beliefs) dapat mempengaruhi niat perilaku untuk memenuhi dan menjawab kebutuhan dari ODD maupun family caregiver.

Dengan berdasar pada kerangka teori di atas, maka focus group discussion dilakukan untuk mendapatkan data mengenai permasalahan yang dihadapi baik oleh ODD maupun caregiver. Sehingga dari permasalahan yang didapat akan dianalisa kebutuhan-kebutuhan ODD dan caregiver yang dipengaruhi oleh faktor-faktor perilaku konsumen sebagai dasar dalam menghasilkan bentuk layanan perawatan yang berbasis kebutuhan. Gambar 4 menunjukkan kerangka teori berdasarkan dengan penjelasan di atas.

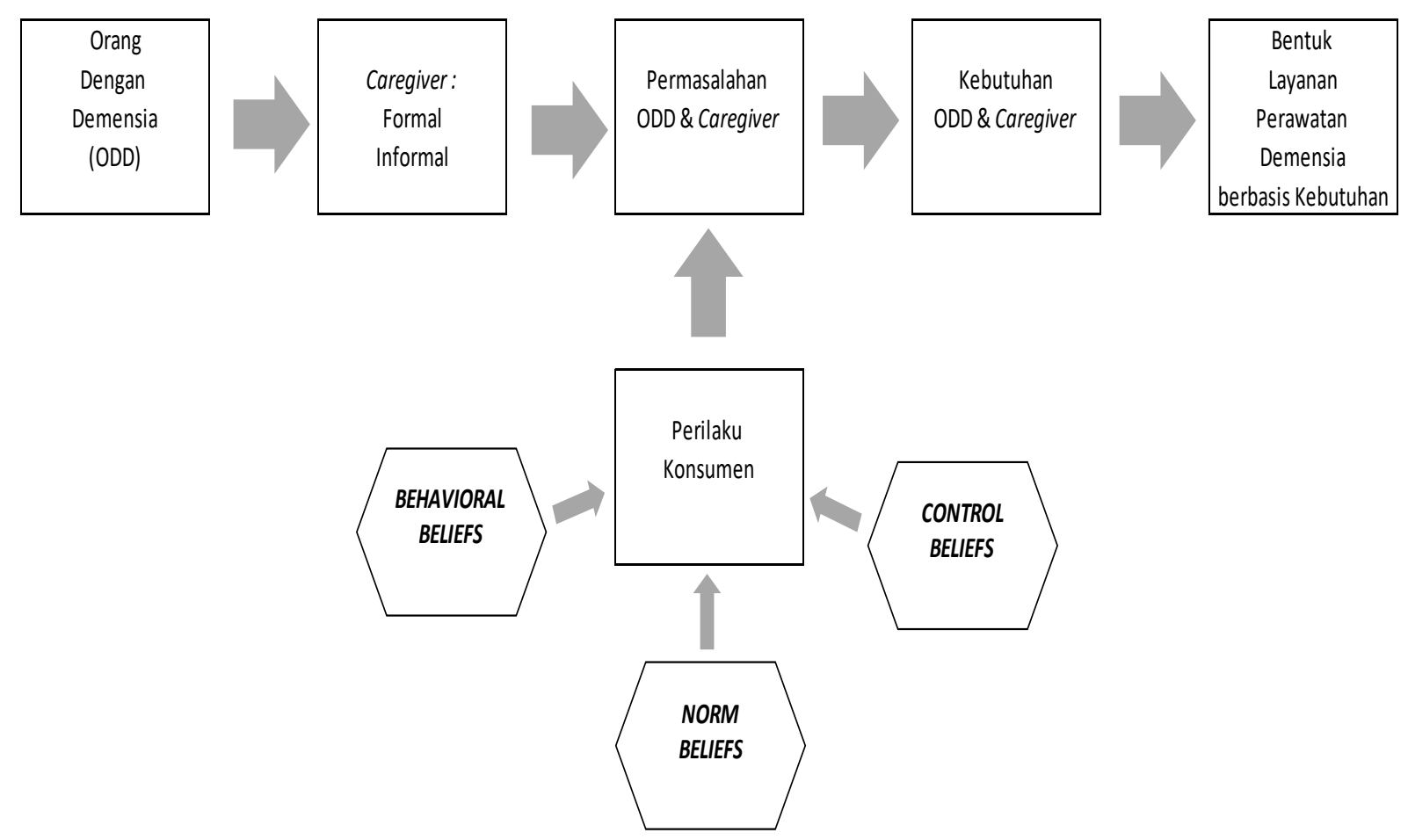

Gambar 4. Kerangka Teori

\section{Metodologi Penelitian}

Penelitian ini menggunakan desain deskriptif yang bertujuan untuk mengidentifikasi masalah, menjelaskan, dan membuat deskripsi tentang suatu gejala atau obyek yang diteliti. Data yang diperoleh dianalisis dengan pendekatan kualitatif. Data dikumpulkan dengan menggunakan 
focus group discussion yang dilakukan dalam 1 sesi yang dipandu oleh 1 moderator. Sesi FGD ini diadakan bekerja sama dengan Alzheimer Indonesia (ALZI) dalam kegiatan caregiver meeting bulanan yang diadakan di ruang serbaguna Golf Hill Terrace Apartment di Pondok Indah, Jakarta Selatan. FGD diikuti oleh 13 responden yang merupakan partisipan ALZI berusia dari 24 tahun hingga 80 tahun dengan berbagai peran terhadap ODD.

Tujuan utama menggunakan focus group discussion adalah untuk memperoleh interaksi yang dihasilkan dari suatu diskusi sekelompok partisipan/responden dalam hal meningkatkan kedalaman informasi yang berguna untuk menyingkap berbagai aspek suatu fenomena kehidupan, sehingga fenomena tersebut dapat didefinisikan dan diberi penjelasan. Data dari hasil interaksi dalam diskusi kelompok tersebut dapat memfokuskan atau memberi penekanan pada kesamaan dan perbedaan pengalaman serta memberikan informasi tentang suatu perspektif. (Afianti 2008). Teknik sampling yang digunakan dalam focus group discussion adalah purposive sampling yang bertujuan agar para responden yang mengikuti FGD dapat memberikan pendapat melalui pengalaman mereka. Kelompok caregiver yang menjadi taret responden adalah informal caregiver atau family caregiver yang mempunyai peran sebagai pasangan, anak, cucu maupun menantu.

Pada pelaksanaan FGD, pertanyaan pada sampel penelitian berupa pertanyaan terbuka (open question), responden dapat dengan bebas mengungkapkan opini terhadap pertanyaan yang dikemukakan yang terdiri dari 4 butir yaitu: (1) Kesulitan utama dalam menghadapi ODD di rumah, (2) Jenis kegiatan luar rumah yang diharapkan bagi ODD, (3) Kondisi dan permasalahan ODD, dan (4) Layanan dukungan bagi keluarga dalam merawat ODD.

\section{Analisis Data}

\section{Karakteristik Responden}

\section{Tabel 1. Karakterisik Responden}

\begin{tabular}{lrr}
\hline \hline \multicolumn{1}{c}{$\begin{array}{c}\text { Karakteristik } \\
\text { Responden }\end{array}$} & $\begin{array}{c}\text { Jumlah } \\
\text { Responden }\end{array}$ & \multicolumn{1}{c}{} \\
\hline \hline Jenis Caregiver & & \\
Caregiver Formal & 0 & $0 \%$ \\
Caregiver Informal & 13 & $100 \%$ \\
\hline
\end{tabular}




\section{Jenis Kelamin}

\begin{tabular}{lrr} 
Pria & 2 & $15 \%$ \\
Wanita & 11 & $85 \%$ \\
\hline
\end{tabular}

\section{Hubungan Caregiver dengan \\ ODD}

\begin{tabular}{lrr} 
Pasangan (Suami/Istri) & 5 & $38 \%$ \\
Anak & 7 & $54 \%$ \\
Menantu & 1 & $8 \%$ \\
\hline
\end{tabular}

\section{Usia Responden}

\begin{tabular}{lrr}
$<30$ tahuns & 1 & $8 \%$ \\
$30-45$ tahun & 6 & $46 \%$ \\
$>45$ tahun & 6 & $46 \%$ \\
\hline Profesi/Pekerjaan & & \\
Ibu Rumah Tangga & 4 & $31 \%$ \\
Pensiunan & 5 & $38 \%$ \\
Karyawan Negeri/Swasta & 2 & $15 \%$ \\
Wiraswasta & 1 & $8 \%$ \\
Mahasiswa & 1 & $8 \%$ \\
\hline
\end{tabular}

Dari Tabel 1, berdasarkan penelitian karakteristik responden menunjukkan bahwa jenis caregiver yang menjadi responden $100 \%$ adalah informal caregiver yaitu family caregiver yang merupakan komunitas dari organisasi Alzheimer Indonesia (ALZI). Family caregiver ini sebagian besar berjenis kelamin wanita, hal ini sesuai dengan hasil penelitian Riasmini (2011), yang menyatakan bahwa mayoritas lansia dirawat oleh anak perempuannya. Mayoritas hubungan antara caregiver dengan ODD sebagai orang tua, hal ini menunjukkan bahwa budaya keluarga besar (extended family) yang merupakan budaya Indonesia masih berkembang. Budaya ini masih memungkinkan lansia untuk tinggal bersama keluarga (anak, menantu, cucu atau anggota keluarga lain). Pada umumnya lansia juga masih memiliki kedudukan yang cukup tinggi sebagai orang tua yang harus dihormati dan dihargai, karena dianggap lebih banyak mempunyai pengalaman, sehingga pendapatnya masih dibutuhkan dalam pengambilan keputusan keluarga (Fitriani 2009). Sebagian besar responden caregiver berusia di atas 30 
tahun yang rata-rata berstatus menikah, ini berarti bahwa sebagian besar family caregiver mempunyai tanggung jawab ganda selain harus mengurus ODD juga harus memperhatikan keluarga intinya sendiri. Sementara profesi dari para caregiver sebagian besar adalah pensiunan $(38 \%)$ dimana rata-rata mereka merupakan pasangan dari ODD, ibu rumah tangga $(31 \%)$ karena harus fokus dalam merawat ODD. Sisanya adalah karyawan dan wiraswasta serta mahasiswa, hal ini menunjukkan bahwa caregiver memiliki tanggung jawab dalam membiayai kebutuhan sehari-hari baik bagi keluarga intinya maupun bagi ODD (Dupuis \& Smale 2004)

\section{Hasil Penelitian}

Berikut adalah hasil dari 4 pertanyaan yang diajukan dalam focus group discussion yang ditujukan untuk dapat memahami secara mendalam tentang permasalahan dan kebutuhan ODD maupun family caregiver berdasarkan pengalaman dari family caregiver.

Pertanyaan mengenai kesulitan utama dalam menghadapi ODD atau merawat ODD di rumah ditujukan untuk dapat menggali tantangan dalam merawat ODD dan dengan berdasar pada pengalaman para family caregiver. Opini responden terhadap pertanyaan ini adalah: ((1) tidak dapat fokus bekerja bagi family caregiver yang masih bekerja sebagai karyawan, sehingga ada yang sampai memutuskan untuk resign dari pekerjaan, (2) tingkat stress yang tinggi bagi family caregiver, (3) ODD merasa bosan dan depresi jika terus-menerus berada di dalam rumah, sehingga butuh usaha yang ekstra bagi family caregiver untuk membawa ODD beraktivitas di luar rumah, (4) kesulitan dalam merawat ODD yang disertai dengan penyakit lainnya, (5) tidak ada waktu khusus bagi family caregiver untuk refreshing/me time.

Pertanyaan berikutnya mengenai jenis kegiatan luar rumah yang diharapkan bagi ODD didasari oleh permasalahan yang timbul bagi ODD dan family caregiver akibat tidak terpenuhinya kebutuhan untuk dapat bersosialisasi di luar rumah. Jawaban dari para responden untuk pertanyaan ini terdiri dari: (1) ODD membutuhkan aktivitas yang dapat menstimulus fungsi kognitif, (2) membutuhkan aktivitas yang menghargai dan memberi peran bagi ODD agar merasa lebih percaya diri, (3) membutuhkan aktivitas di akhir pekan bagi ODD yang memungkinkan family caregiver dapat memperoleh me time-nya, (4) membutuhkan aktivitas layanan perawatan yang customize/personalize.

Selanjutnya pertanyaan yang diajukan kepada para responden adalah kondisi dan permasalahan ODD secara umum hal ini dilakukan untuk mendapatkan gambaran mengenai kondisi ODD 
yang berdampak pada family caregiver. Opini dari responden pertanyaan ini adalah: (1) kesulitan dalam merawat jika tidak memahami latar belakang dan riwayat kesehatan ODD sehingga membuat ODD merasa tidak nyaman dan menarik diri dan pada akhirnya zona nyaman ODD semakin sempit, (2) kesulitan dalam merawat ODD jika family caregiver tidak mempunyai kapabilitas dalam pengetahuan dan keahlian tentang penanganan demensia yang disesuaikan dengan jenis, tahapan, dan dampak demensianya, (3) kesulitan dalam merawat ODD saat menghadapi ketidaknyamanan ODD beraktivitas di luar rumah atau public area yang disebabkan kurangnya awareness masyarakat terhadap demensia.

Pertanyaan berikutnya mengenai layanan dukungan bagi family caregiver dalam merawat ODD ditujukan untuk mengetahui bentuk layanan seperti apa yang sangat dibutuhkan dan dirasa efektif bagi family caregiver. Hal ini didasari oleh permasalahan baik yang dihadapi oleh ODD maupun family caregiver dalam kegiatan merawat ODD. Untuk pertanyaan ini, opini dari para responden sebagai berikut: (1) membutuhkan support group bagi family caregiver untuk berbagi pengalaman dan pengetahuan tentang kegiatan merawat demensia, (2) membutuhkan layanan perawatan yang dapat dilakukan di rumah atau paling tidak layanan perawatan luar rumah yang tidak mengharuskan ODD menginap di fasilitas perawatan, (3) membutuhkan layanan perawatan bagi ODD yang disesuaikan dengan tingkat demensianya. (4) membutuhkan area untuk bersosialisasi bagi ODD.

\section{Hubungan antara faktor yang mempengaruhi perilaku konsumen dalam menjawab kebutuhan ODD \& Caregiver}

Berdasarkan hasil jawaban dari para responden atas 4 pertanyaan yang diajukan tersebut, maka dikelompokkan menjadi dua yaitu permasalahan dan kebutuhan dari sisi ODD serta permasalahan dan kebutuhan dari sisi family caregiver. Dan selanjutnya akan dianalisa dengan faktor-faktor yang mempengaruhi perilaku konsumen berdasarkan Theory Planned Behavior, keyakinan perilaku (behavioral beliefs), keyakinan normatif (normative beliefs), dan keyakinan bahwa suatu perilaku dapat dilaksanakan (control beliefs) melalui permasalahan bagi ODD maupun family caregiver dapat mempengaruhi niat perilaku untuk memenuhi dan menjawab kebutuhan dari ODD maupun family caregiver. Ke-3 faktor ini dibagi menjadi faktor internal yaitu behavioral beliefs dan faktor eksternal meliputi normative beliefs dan control beliefs. 


\section{Dampak Faktor Keyakinan Perilaku (Behavioral Beliefs) terhadap Permasalahan ODD \& Family Caregiver}

Keyakinan perilaku/behavioral beliefs dipengaruhi oleh 3 faktor latar belakang yaitu faktor personal, sosial, dan informasi, yang melatarbelakangi perilaku konsumen. Dari hasil focus group discussion maka didapatkan beberapa permasalahan bagi ODD yang didasari oleh faktor keyakinan perilaku ini adalah sebagai berikut: (1) jenis dan tahapan demensia yang dimiliki ODD memberi dampak pada kesulitan bagi family caregiver dalam merawat ODD jika tidak didukung dengan pengetahuan dan keahlian dalam merawat demensia, (2) keinginan ODD untuk merasa dihargai dan diberi peran tidak sepenuhnya dapat diakomodasi oleh family caregiver karena keterbatasan waktu dan pengetahuan mereka.

Sedangkan faktor keyakinan perilaku yang mempengaruhi permasalahan family caregiver dalam merawat ODD adalah (1) minimnya pengetahuan dan keahlian yang dimiliki family caregiver serta terbatasnya waktu dapat mempengaruhi tingkat stress yang tinggi terhadap family caregiver. Dari hasil FGD diketahui bahwa kebanyakan family caregiver yang adalah anak-anak dari pada ODD secara terus menerus tinggal bersama dan merawat ODD dalam jangka waktu lama. Hal ini disebabkan tidak semua anak dari para ODD tersebut memiliki waktu secara khusus, kemampuan secara ekonomi, dan keinginan merawat untuk balas budi terhadap orang tua ODDnya. (2) minimnya waktu untuk refreshing/me time bagi family caregiver dapat menimbulkan tingkat stress yang tinggi. Bahkan bagi family caregiver yang sudah menikah sering berdampak pada kurangnya perhatian bagi keluarga dari family caregiver tersebut. (3) kehilangan pekerjaan bagi family caregiver yang sambil bekerja disebabkan karena perawatan ODD membuat waktu dan perhatiannya menjadi lebih tersita terhadap ODD dbanding dengan pekerjaannya. Sehingga ada beberapa family caregiver yang pada akhirnya memutuskan untuk berhenti dari pekerjaannya.

\section{Dampak Faktor Keyakinan Normatif (Normatif Beliefs) terhadap Permasalahan ODD \& Family Caregiver}

Berdasarkan faktor keyakinan normatif (normatif beliefs) yang berkaitan langsung dengan pengaruh lingkungan sosial didapatkan beberapa permasalahan bagi ODD meliputi: (1) tidak terpenuhinya kebutuhan untuk bersosialisasi dalam zona nyamannya ODD, yang disebabkan keengganan ODD beraktivitas di luar rumah khususnya di public area karena merasa tidak nyaman akibat kurangnya kesadaran masyarakat tentang perlakuan bagi ODD. Padahal 
kebutuhan bersosialisai di luar rumah memberi dampak positif bagi ODD untuk tetap merasa bahagia, dihargai, dan percaya diri. (2) tidak terpenuhinya kebutuhan untuk memperoleh aktivitas yang dapat menstimulus fungsi kognitif, afektif, dan psikomotorik. Dengan terbatasnya waktu, pengetahuan dan keahlian family caregiver dalam menyediakan aktivitas yang menstimulus ini akan berdampak buruk karena tidak dapat menahan lajunya tahapan demensia.

Sementara itu faktor keyakinan normatif yang mempengaruhi permasalahan family caregiver adalah pandangan negatif dari pihak keluarga maupun lingkungan jika ODD tidak dirawat oleh keluarga sendiri membuat family caregiver akan berupaya semaksimal mungkin tetap merawat orang tua ODDnya meskipun tidak mempunyai waktu, pengetahuan, dan kemampuan yang baik mengenai demensia.

\section{Dampak Faktor Keyakinan Perilaku Dapat Dilaksanakan (Control Beliefs) terhadap Permasalahan ODD \& Family Caregiver}

Faktor control beliefs sangat dipengaruhi oleh (a) pengalaman melakukan perilaku yang sama sebelumnya atau dari orang lain, (b) pengetahuan, ketrampilan, dan pengalaman, dan (c) ketersediaan waktu untuk melaksanakan. Hasil penelitian menunjukkan bahwa dari hasil FGD, para family caregiver (1) sangat membutuhkan support group untuk berbagi pengalaman dan pengetahuan tentang kegiatan merawat demensia. Hal ini menunjukkan family caregiver dengan berdasar pada pengalaman orang lain, membutuhkan pengetahuan yang akan menunjang kegiatan caregiving mereka agar sesuai dengan kebutuhan ODD. Selain itu hasil penelitian menunjukkan family caregiver (2) membutuhkan layanan perawatan yang dapat dilakukan di rumah atau paling tidak layanan perawatan luar rumah yang tidak mengharuskan ODD menginap di fasilitas perawatan dan (3) membutuhkan layanan perawatan bagi ODD yang disesuaikan dengan tingkat demensianya. Poin no 2 dan 3 menunjukkan bahwa family caregiver membutuhkan layanan perawatan eksternal karena kurangnya ketersediaan waktu dan pengetahuan untuk melaksanakan perawatan yang efektif bagi ODD.

\section{Kesimpulan}

Berdasarkan hasil pembahasan dan analisa di atas, dapat diambil kesimpulan sebagai berikut karakteristik family caregiver yang mempunyai hubungan dengan ODD sebagai anak/menantu dan pasangan, mayoritas berusia di atas 30 tahun berjenis kelamin wanita, dan rata-rata 
menikah. Sebagian besar ada yang tidak bekerja (ibu rumah tangga dan pensiunan) dan ada yang sambil bekerja (karyawan dan wiraswasta).

Dari hasil penelitian, timbulnya permasalahan bagi ODD maupun family caregiver dipengaruhi oleh perilaku konsumen dengan pendekatan Theory Planned Behavior yang terdiri dari behavioral beliefs, normative beliefs, dan control beliefs. Ke-3 faktor ini mempengaruhi perilaku konsumen dalam menjawab kebutuhan ODD maupun family caregiver. Maka dapat diambil kesimpulan bahwa kebutuhan dari ODD maupun family caregiver dalam merawat ODD dapat dikelompokkan sebagai berikut:

\section{Kebutuhan ODD}

(1) Membutuhkan aktivitas yang dapat menstimulus fungsi kognitif, afektif, dan psikomotorik bagi ODD untuk dapat menahan laju tahapan demensianya.

(2) Membutuhkan perawatan yang khusus yang disesuaikan dengan latar belakang, kondisi dan tahapan demensianya,

(3) Membutuhkan area untuk bersosialiasi yang nyaman di luar rumah untuk dapat mengurangi tingkat depresi yang tinggi dari ODD.

\section{Kebutuhan Family Caregiver}

(1) Membutuhkan keahlian maupun pengetahuan caregiver dalam merawat ODD sesuai dengan latar belakang, kondisi, dan tahapan demensianya,

(2) Membutuhkan waktu luang untuk bersantai atau me time dan waktu bagi keluaga sendiri bagi family caregiver yang sudah menikah.

(3) Keinginan untuk tetap dapat merawat dan tinggal bersama ODD agar tetap dapat berbakti pada orang tua dan tidak dianggap membuang orang tua.

Berdasarkan kesimpulan dari kebutuhan-kebutuhan baik yang dilihat dari sisi ODD maupun dari sisi family caregiver diharapkan dapat memberikan informasi tentang kebutuhan akan layanan perawatan yang dapat mengakomodasi seluruh kebutuhan secara efektif dan optimal. 


\section{Daftar Pustaka}

Ajzen I. (2005), Attitudes, personality, and behavior, Open University Press, New York. Brodaty H. (2009), "Family caregivers of people with dementia", Dialogues Clin Neurosci, 11(2) (June):217-228.

Bumagin VE. (2009), Caregiving, Springer, New York.

Cassie KM and Sanders S. (2008), "Familial caregivers of older adults", Journal of Gerontological Social Work, 50 (October): 293-320.

Dementia in the Asia Pacific Region. King's College London:Alzheimer's Disease International (ADI), 2014.

Dr. N.W. Suriastini, M.Phil et.al, “Angka Prevalensi Demensia: Perlu Perhatian Kita Semua”, SurveyMETER Policy Brief, (Maret 2016): 3.

Dupuis, SL, Epp T, dan Smale B. (2004), Caregivers of Pearson with Dementia: Roles, Experiences, Supports and Coping. A Literature Review, Murray Alzheimer Research and Education Program, University of Waterloo.

Fishbein MA and Ajzen I. (1975), Belief, attitude, intention and behaviour: An introduction to theory and research, Reading, MA: Addison-Wesley.

Fitriani, E., 2009. Lansia dalam Keluarga dan Masyarakat. endafitriani. diperoleh (11 Agustus 2018).

González-Salvador MT et.al. (1999), "The stress and psychological morbidity of the Alzheimer patient caregiver", Int J Geriatr Psychiatry, 14(9) (September):701-10. Kumalasari DN. (2017), "Hubungan Antara Burden Family Caregiver Dengan Kualitas Hidup Family Caregiver Dalam Merawat Pasien Demensia Di RSUP Dr. Sardjito Yogyakarta", Electronic Theses \& Dissertations (ETD) UGM.

Novia DRM dan Putri WD. (2016), "Menkes: Lansia yang Sehat Jauh dari Demensia”, http://www.republika.co.id/, (November 2017).

Poulshock SW and Deimling GT. (1984), "Families caring for elders in residence: issues in the measurement of burden", Journal of Gerontology, 39(2). (March): 230-9.

Riasmini, M., 2011. Pengalaman Keluarga dan Tenaga Kesehatan dalam Perawatan Lanjut Usia. Risbinakes. Jakarta.

World Alzheimer Report The Global Impact of Dementia: An analysis of prevalence, incidence, cost and trends updates ADI's global dementia data", King's College London:Alzheimer's Disease International (ADI), 2015.

World Health Organization Website, https://www.who.int/, (20 Juni 2017). 